\title{
Epidemiology of soccer injuries in Korea women national team for 5 years
}

\author{
Chang-Hwa Joo* \\ Department of Sport Science, Kangwon National University, Chuncheon, Korea
}

The purpose of this study was to analyze the characteristics of injuries in female national soccer players. The injuries data were recorded by Korea Football Association medical staff using the Daily Medical Report provided by the Asian Football Confederation during a total 21 training camps and friendly and official matches from January 2014 to December 2018. A total of 483 players in the national team training camps and matches participated in the study, of which 377 players experienced more than one injury. Sports injuries accounted for $89 \%$ of the total 1,019 injuries; general diseases accounted for the remaining $11 \%$. The number of injuries per 1,000 exposure hours was higher in matches than in training sessions. Most injuries that occurred during training and matches involved the lower extremities $(79 \%)$. The most common injury diagnosed during training and matches was muscle rigidity $(45 \%)$, followed by contusions/hematomas/bruises (22\%) and sprain (15\%). The largest proportions of injuries in terms of absence from soccer play were minimal injury $(67 \%)$, followed by mild $(29 \%)$, moderate $(3.5 \%)$, and severe (1\%). As conclusion, the characteristics of injuries during training sessions and matches were different. Rehabilitation and injury prevention programs need to developed for female soccer players to improve the players' performance.

Keywords: Soccer, Women national team, Injury

\section{INTRODUCTION}

Elite male soccer players require a high level of physical fitness as they have to run approximately 10-12 km per match, and also run a series of sprints during the match (Dellal et al., 2011). Although female athletes also run approximately $10 \mathrm{~km}$ during a match, the amount of high-intensity exercise, such as sprints, is lower than that of male players (Datson et al., 2017). The fact that female players perform fewer high-intensity exercises than male players may be attributed to differences in physical characteristics, such as muscle mass. However, the proportion of high-intensity activity during a match was higher in female (6\%) compared to male (3\%) players (Datson et al., 2017; Dellal et al., 2011). Therefore, both male and female players need to include high-intensity exercises, such as sprints, in the training period to improve their performance in matches.

Soccer has a higher incidence of injuries than other sports due to intensive movements, such as jumps, tackles, and sprints, which are performed during the match (Stevenson et al., 2000; Wong and Hong, 2005). In particular, the frequency of injuries is higher during matches than during general team training (Junge and Dvorak, 2004). Most soccer players experience an injury at least once in a season that leads to their withdrawal from participating in exercises for a period (Waldén et al., 2015). Soccer players are injured more often in the lower extremities as compared to the upper extremities, and the most frequently injured location is the ankle (Le Gall et al., 2008). Injuries occur more frequently in the regular season $(66.5 \%)$ than in the preseason $(26.6 \%)$ and postseason $(6.8 \%)$ (Roos et al., 2017).

The characteristics of injuries in soccer players may be related to the performance level of the players. As high-level soccer players are required to perform more physically demanding activities, such as high-intensity exercise (Rampinini et al., 2007), the frequency and severity of injuries may be different in high-level soccer players and lower-level soccer players. To the best of the author's knowledge, there are few studies that demonstrate the char-
${ }^{*}$ Corresponding author: Chang-Hwa Joo (iD https://orcid.org/0000-0002-7429-3104 Department of Sport Science, Kangwon National University, 1 Kangwondaehak-gil, Chuncheon 24341, Korea

Email: ju217@hanmail.net

Received: November 25, 2021 / Accepted: December 19, 2021
This is an Open Access article distributed under the terms of the Creative Commons Attribution Non-Commercial License (https://creativecommons.org/licenses/by-nc/4.0/) which permits unrestricted non-commercial use, distribution, and reproduction in any medium, provided the original work is properly cited. 
acteristics of injuries in highest-level soccer players, such as national team players. A previous study on the characteristics of injuries in the Korean male national team demonstrated that $85 \%$ of injuries occurred in lower extremities, and the most frequent types of injuries were contusions, muscle rigidity, and sprains (HwangBo and Joo, 2019). Most of the previous studies on the characteristics of injuries focus on high-level male soccer players (Dauty and Collon, 2011; Ekstrand et al., 2011; Pfirrmann et al., 2016), and there are no studies on the characteristics of injuries in female players, especially national team soccer players.

Dick et al. (2007) conducted epidemiologic studies on the characteristics of female college soccer players from the 1988-1989 season through the 2002-2003 season. The results of the study showed that the frequency of preseason injuries was 3 times higher than that of in-season injuries; $70 \%$ of injuries involved the lower extremities, and the most common injury types were ankle ligament sprains, knee internal derangements, and concussions. Roos et al. (2017) studied the differences in the characteristics of injuries between male and female college soccer players over 6 seasons. There was no difference in the frequency of injuries between male and female soccer players during practice and matches, and the most commonly diagnosed injury was a sprain in lower extremities. However, the number of concussions were higher in female soccer players than in male soccer players.

The prevention of such injuries is important as these injuries can affect the players' entire career. The best way to prevent injuries is to improve physical fitness, for example, by improving muscle strength. In addition, an appropriate rehabilitation program should be composed so that the players can return to training soon after an injury. In order to compose a rehabilitation program for injury prevention and to promote rapid recovery after injury, it is necessary to understand the characteristics of the injuries. Therefore, the purpose of this study was to analyze the characteristics of injuries in female national soccer players.

\section{MATERIALS AND METHODS}

\section{Subjects}

The players were part of the Korean women's national team participating in training camps and matches from January 2014 to December 2018. The Korea Football Association (KFA) medical staff recorded the injuries that occurred during a total of 21 training camps and friendly and official matches.

\section{Measurements}

The injuries were recorded by the medical staff using the Daily Medical Report provided by the Asian Football Confederation (Hwang-Bo and Joo, 2019). The characteristics of the injuries (type of injury, location of injury, location of injury by playing position, and diagnosis of injury) were recorded. Only the injuries that occurred during the national team's training camps and matches were recorded. In the event of an injury during training or a match, a memo was immediately prepared, and recorded after discussion with two or more medical staff in the evening. The injuries that were difficult to diagnose were decided by consensus during the KFA Medical Team's meeting after the camps. Severity of injury was categorized based on the number of days that players did not participate in training after injury: minimal (1-3 days), mild (4-7 days), moderate (8-28 days), severe ( $>28$ days). The number of injuries per 1,000 exposure hours was calculated using the following formula: (number of injuries/exposure hours) $\times$ 1,000 .

\section{Statistical analysis}

All statistical analyses were performed using SPSS ver. 17.0 (SPSS Inc., Chicago, IL, USA). Frequency analysis and descriptive statistical analysis were conducted to determine the differences in injury characteristics. Injury characteristics were presented as absolute numbers and percentages.

\section{RESULTS}

\section{Number of injured players}

A total of 483 players in the national team training camps and matches participated in the study for the 5-year period, of which 377 players experienced more than one injury. More than $70 \%$ of the players were injured during matches or training sessions in the 5-year period (Table 1).

\section{Type of injuries}

The occurrence of sports injuries was significantly higher than that of general diseases, such as diarrhea. Sports injuries accounted for $89 \%$ of the total 1,019 injuries; general diseases accounted for

Table 1. The number of injured players

\begin{tabular}{lcccccc}
\hline & 2014 & 2015 & 2016 & 2017 & 2018 & Overall \\
\hline Players & 85 & 141 & 89 & 93 & 75 & 483 \\
Injured players & $69(81.2)$ & $100(70.9)$ & $70(78.7)$ & $76(81.7)$ & $62(82.7)$ & $377(78.1)$
\end{tabular}

Values are presented as number (\%). 
the remaining $11 \%$ (Table 2).

\section{Location of injuries}

Absolute number of injuries were 583 and 321 during training and matches, respectively. But the number of injuries per 1,000 exposure hours was higher in matches than in training sessions. Most injuries that occurred during training and matches involved the lower extremities (79\%) (Table 3).

\section{Location of injuries by playing position}

The position with the most injuries was defender (DF), followed by forward (FW), midfielder (MF), and goalkeeper (GK). However, the frequency of injuries per player was high in the following order; FW, DF, MF, and GK. In the case of GK, more injuries per player occurred in the upper extremities than in other locations (Table 4).

Table 2. Types of injuries

\begin{tabular}{lcccccc} 
& 2014 & 2015 & 2016 & 2017 & 2018 & Overall \\
\hline Sports injuries & $161(87.5)$ & $218(94.8)$ & $192(88.1)$ & $177(92.7)$ & $156(79.6)$ & $904(88.7)$ \\
Other diseases & $23(12.5)$ & $12(5.2)$ & $26(11.9)$ & $14(7.3)$ & $40(20.4)$ & $115(11.3)$ \\
Total & 184 & 230 & 218 & 191 & 196 & 1,019 \\
\hline
\end{tabular}

Values are presented as number (\%).

Table 3. Distribution of injuries in accordance with body part

\begin{tabular}{|c|c|c|c|c|c|c|}
\hline \multirow{3}{*}{$\begin{array}{l}\text { Body } \\
\text { part }\end{array}$} & \multicolumn{2}{|c|}{ Training } & \multicolumn{2}{|c|}{ Match } & \multicolumn{2}{|c|}{ Overall } \\
\hline & \multicolumn{2}{|c|}{ Injuries in Injuries per } & \multicolumn{2}{|c|}{ Injuries in Injuries per } & \multicolumn{2}{|c|}{ Injuries in Injuries per } \\
\hline & sample & $1,000 \mathrm{hr}$ & sample & $1,000 \mathrm{hr}$ & sample & $1,000 \mathrm{hr}$ \\
\hline $\begin{array}{l}\text { Head/ } \\
\text { trunk }\end{array}$ & 83 & 2.5 & 35 & 4.5 & 118 & 2.9 \\
\hline $\begin{array}{r}\text { Upper } \\
\text { limb }\end{array}$ & 41 & 1.3 & 31 & 4.0 & 72 & 1.8 \\
\hline $\begin{array}{r}\text { Lower } \\
\text { limb }\end{array}$ & 459 & 14.0 & 255 & 32.6 & 714 & 17.6 \\
\hline Total & 583 & 17.8 & 321 & 41.1 & 904 & 22.3 \\
\hline
\end{tabular}

Values are presented as number.

\section{Diagnoses of injuries}

The most common injury diagnosed during training was muscle rigidity, followed by contusion/hematoma/bruise and sprain. However, contusions/hematomas/bruises were most common during matches, followed by muscle rigidity and sprain (Table 5).

\section{Severity of injuries}

The largest proportions of injuries in terms of absence from soccer play were minimal injury (67\%). Twenty-nine percent of the injuries ( $\mathrm{n}=33$ ) lasted from 4 to 7 days. Only four moderate injuries occur during training $(n=3)$ and matches $(n=4)$. Ligamentous rupture was the greatest time-loss injury (Table 6).

\section{DISCUSSION}

This study was conducted to analyze the characteristics of injuries occurring during training sessions and matches in the Korean female national soccer team. The frequency and types of injuries in the women's national team were similar to those in the men's national team, but the characteristics of injuries during training sessions and matches were different.

Most of the injuries that occurred during the national team callup period were sports injuries and were not caused by other diseases, such as cold and diarrhea. These results were similar to those of the previous studies that investigated the frequency of injuries in male national soccer players (Hwang-Bo and Joo, 2019). In general, most injuries in elite soccer teams are sports injuries. In the case of national teams in particular, the higher number sports injuries when compared with general diseases can be attributed to the method of recruiting players. In other words, the national team does not call up players with common diseases, therefore, the number of common diseases was lower during the call-up period.

In agreement with the results of several studies (Del Coso et al., 2018; Wong and Hong, 2005), the most commonly injured location was lower extremities followed by the head-and-trunk-region

Table 4. Distribution of injuries in accordance with body part across playing positions

\begin{tabular}{|c|c|c|c|c|c|c|c|c|c|c|c|c|}
\hline \multirow{2}{*}{ Body part } & \multicolumn{3}{|c|}{ FW (96) } & \multicolumn{3}{|c|}{ MF (163) } & \multicolumn{3}{|c|}{$\mathrm{DF}(167)$} & \multicolumn{3}{|c|}{ GK (57) } \\
\hline & $\mathrm{T}$ & M & Total & $\mathrm{T}$ & $M$ & Total & $\mathrm{T}$ & $M$ & Total & T & $M$ & Total \\
\hline Head/trunk & 21 & 11 & 32 & 20 & 8 & 28 & 18 & 13 & 31 & 25 & 4 & 29 \\
\hline Upper limb & 10 & 14 & 24 & 6 & 6 & 12 & 13 & 4 & 17 & 12 & 4 & 16 \\
\hline Lower limb & 135 & 95 & 230 & 145 & 71 & 216 & 158 & 86 & 244 & 20 & 5 & 25 \\
\hline Total & 166 & 120 & $286(31.6)$ & 171 & 85 & 256 (28.3) & 189 & 103 & 292 (32.3) & 57 & 13 & $70(7.8)$ \\
\hline
\end{tabular}

Values are presented as number $(\%)$.

FW, forward; MF, midfielder; DF, defender; GK, goalkeeper; T, training; M, match. 
Table 5. Distribution of diagnoses

\begin{tabular}{|c|c|c|c|c|c|c|c|c|c|c|c|c|c|c|c|c|c|c|}
\hline \multirow{2}{*}{ Variable } & \multicolumn{3}{|c|}{2014} & \multicolumn{3}{|c|}{2015} & \multicolumn{3}{|c|}{2016} & \multicolumn{3}{|c|}{2017} & \multicolumn{3}{|c|}{2018} & \multicolumn{3}{|c|}{ Overall } \\
\hline & $\mathrm{T}$ & M & Total & T & M & Total & $\mathrm{T}$ & $M$ & Total & $\mathrm{T}$ & $M$ & Total & T & M & Total & T & M & Total \\
\hline Concussion & 0 & 1 & 1 & 0 & 0 & 0 & 0 & 1 & 1 & 0 & 0 & 0 & 0 & 0 & 0 & 0 & 2 & $2(0.2)$ \\
\hline Fracture & 0 & 0 & 0 & 0 & 0 & 0 & 0 & 1 & 1 & 0 & 0 & 0 & 0 & 0 & 0 & 0 & 1 & $1(0.1)$ \\
\hline Stress fracture & 0 & 0 & 0 & 0 & 0 & 0 & 0 & 0 & 0 & 0 & 0 & 0 & 0 & 0 & 0 & 0 & 0 & $0(0)$ \\
\hline Other bone injuries & 0 & 0 & 0 & 1 & 0 & 1 & 0 & 0 & 0 & 0 & 0 & 0 & 0 & 0 & 0 & 1 & 0 & $1(0.1)$ \\
\hline Dislocation/subluxation & 0 & 0 & 0 & 0 & 1 & 1 & 0 & 0 & 0 & 1 & 1 & 2 & 0 & 1 & 1 & 1 & 3 & $4(0.4)$ \\
\hline Ligament rupture & 0 & 0 & 0 & 0 & 0 & 0 & 0 & 1 & 1 & 0 & 0 & 0 & 0 & 1 & 1 & 0 & 2 & $2(0.2)$ \\
\hline Sprain & 20 & 11 & 31 & 12 & 24 & 36 & 9 & 9 & 18 & 16 & 12 & 28 & 11 & 13 & 24 & 68 & 69 & $137(15.2)$ \\
\hline Lesion of meniscus/cartilage & 0 & 0 & 0 & 0 & 0 & 0 & 0 & 1 & 1 & 0 & 0 & 0 & 0 & 0 & 0 & 0 & 1 & $1(0.1)$ \\
\hline muscle rupture & 0 & 0 & 0 & 0 & 2 & 2 & 0 & 0 & 0 & 0 & 0 & 0 & 0 & 0 & 0 & 0 & 2 & $2(0.2)$ \\
\hline Contusion/hematoma/bruise & 34 & 19 & 53 & 13 & 43 & 56 & 10 & 23 & 33 & 9 & 24 & 33 & 7 & 18 & 25 & 73 & 127 & $200(22.1)$ \\
\hline Arthritis/synovitis/bursitis & 8 & 0 & 8 & 0 & 0 & 0 & 2 & 0 & 2 & 8 & 0 & 8 & 8 & 1 & 9 & 26 & 1 & $27(3.0)$ \\
\hline Fasciitis/aponeurosis injury & 9 & 0 & 9 & 1 & 1 & 2 & 11 & 2 & 13 & 4 & 0 & 4 & 4 & 2 & 6 & 29 & 5 & $34(3.8)$ \\
\hline Laceration/abrasion/skin lesion & 0 & 1 & 1 & 0 & 0 & 0 & 1 & 0 & 1 & 0 & 2 & 2 & 1 & 0 & 1 & 2 & 3 & $5(0.6)$ \\
\hline Abrasion & 0 & 0 & 0 & 2 & 0 & 2 & 0 & 0 & 0 & 0 & 0 & 0 & 0 & 0 & 0 & 2 & 0 & $2(0.2)$ \\
\hline Muscle rigidity & 27 & 17 & 44 & 62 & 12 & 74 & 93 & 18 & 111 & 75 & 20 & 95 & 67 & 15 & 82 & 324 & 82 & 406 (44.9) \\
\hline Muscle cramps & 1 & 0 & 1 & 15 & 7 & 22 & 1 & 1 & 2 & 1 & 2 & 3 & 1 & 5 & 6 & 19 & 15 & $34(3.8)$ \\
\hline Muscle contusion & 13 & 0 & 13 & 15 & 7 & 22 & 7 & 1 & 8 & 2 & 0 & 2 & 1 & 0 & 1 & 38 & 8 & $46(5.1)$ \\
\hline Total & 112 & 49 & 161 & 121 & 97 & 218 & 134 & 58 & 192 & 116 & 61 & 177 & 100 & 56 & 156 & $583(64$. & 321 (35. & $904(100)$ \\
\hline
\end{tabular}

Values are presented as number (\%).

$\mathrm{T}$, training; $\mathrm{M}$, match.

Table 6. Severity of injuries

\begin{tabular}{lccc}
\hline Severity of injury & Training & Match & Total \\
\hline Minimal (1-3 days) & $42(72.4)$ & $35(61.4)$ & $77(67)$ \\
Mild (4-7 days) & $13(22.4)$ & $20(35)$ & $33(28.6)$ \\
Moderate (8-28 days) & $3(5.2)$ & $1(1.8)$ & $4(3.5)$ \\
Severe (> 28 days) & $0(0)$ & $1(1.8)$ & $1(0.9)$ \\
\hline
\end{tabular}

Values are presented as number (\%).

and the upper extremities. These results may be related to the manner in which a soccer player handles the ball using the lower extremities, including the foot, knee and thigh, and to the load on the lower extremities from high-intensity activities, such as jumping. The number of injuries being higher in the head and trunk region than in the upper extremities can be attributed to the fact that there is a lot of physical contact with opponents, which leads to head-and-trunk-region injuries. Indeed, it was found that most injuries during soccer matches and training were caused by contact with players (33\%) (Stubbe et al., 2015).

In this study, the number of injuries per 1,000 exposure hours was 17.8 and 22.3 during training and matches, respectively. This number was higher than that of European male (Netherland, 6.2; Sweden, 7.6; Denmark, 14.2) (Hägglund et al., 2005; Hägglund et al., 2006; Stubbe et al., 2015) and female soccer players (train- ing session, 6.8; matches, 20) (Dick et al., 2007). The trend of a high incidence of injuries during matches was similar to that in previous studies, but the frequency was higher in the current study, particularly during training. This can be attributed to the difference in the level of the players. In the previous study, elite players such as professional soccer players were targeted, whereas in the current study, the highest-level players were targeted. Due to the nature of the national team, players with the highest level of athletic performance from each team were called and trained. In the national team, the players performed vigorous exercises in a physically and psychologically tense state during the training period in order to participate in the national matches. The current study finding that $78 \%$ of players were injured during a call-up period supports this fact. Indeed, the injury rate was higher compared with the elite female team (Del Coso et al., 2018).

In terms of injuries by playing position, the most injuries occurred in lower extremities. The position associated with the most injuries per player was FW. Injury occurrence characteristics were also found to be closely related to the playing style for the position. The FW position spent more time high-intensity movements during matches (Rampinini et al., 2007), which explains the high number of injuries. In addition, most of the players in the GK position experienced injuries in the upper extremities even though 
fewer players were called compared to other positions. In particular, many of these injuries occurred during training, which is closely related to the training methods for GK players. In the case of the GK position, while the feet are more frequently used for build-up play and goal-kicks during the game, and they are required to perform exercises, such as diving to save a goal, which results in a high load being applied on the upper extremities during training. Therefore, the incidence of injuries is relatively high in the GK position when compared with other positions.

The most frequent types of injuries diagnosed in the female national soccer players were contusion/hematoma/bruises, muscle rigidity, and muscle contusion. These results were consistent with the male national soccer players (Hwang-Bo and Joo, 2019). Interestingly, there are differences in the diagnosis of injuries occurring during training and matches. Muscle rigidity was the most common injury during training, whereas the frequency of contusions/hematomas/bursitis were highest during matches. This phenomenon can be attributed to the differences in exercise performance during training and matches for female soccer players. In other words, the higher incidence of contusions/hematomas/bursitis during match is due to greater contact with opponent players when compared with training. In addition, the higher occurrence of muscle rigidity is related to the high-intensity exercise performed during training in order to improve physical fitness for successful performance during matches.

The severity of the injuries was similar in training sessions and matches in the current study. However, injuries requiring absence from training for more than 28 days occurred only during matches. The pattern of severity of injuries in this study was different from that of other study. Injuries with the largest proportion in this study were minimal injuries, followed by mild, moderate, and severe injuries. In a previous study, the most common injuries were moderate followed by mild, minimal, and severe injuries (Stubbe et al., 2015). The difference in the results of these studies may be due to the training period and the composition of the players. Unlike elite players, national players have a lower risk of serious injuries because of the short period of training camps and matches. In addition, a well-trained medical support team is present during training sessions; therefore, the injuries can be treated promptly, which may reduce the possibility of occurrence of serious injuries. On the other hand, as the players are highly motivated to participate in matches, they tend to take shorter recovery breaks and return to training sessions early, disregarding the severity of their injuries.

In conclusion, the injury characteristics of female national play- ers were similar to those of male professional soccer players and national team players. However, there were some differences in the types of injuries occurring during training sessions and during matches in female national players. Based on these results, rehabilitation and injury prevention programs need to developed for female soccer players to improve the players' performance. In future research, it is necessary to analyze the age-specific injury characteristics of national or elite female soccer players in order to improve performance by preventing injuries, and developing targeted rehabilitation programs.

\section{CONFLICT OF INTEREST}

No potential conflict of interest relevant to this article was reported.

\section{ACKNOWLEDGMENTS}

This study was supported by 2021 Research Grant from Kangwon National University.

\section{REFERENCES}

Datson N, Drust B, Weston M, Jarman IH, Lisboa PJ, Gregson W. Match physical performance of elite female soccer players during international competition. J Strength Cond Res 2017;31:2379-2387.

Dauty M, Collon S. Incidence of injuries in French professional soccer players. Int J Sports Med 2011;32:965-969.

Del Coso J, Herrero H, Salinero JJ. Injuries in Spanish female soccer players. J Sport Health Sci 2018;7:183-190.

Dellal A, Chamari K, Wong DP, Ahmaidi S, Keller D, Barros R, Bisciotti GN, Carling C. Comparison of physical and technical performance in European soccer match-play: FA Premier League and La Liga. Eur J Sport Sci 2011;11:51-59.

Dick R, Putukian M, Agel J, Evans TA, Marshall SW. Descriptive epidemiology of collegiate women's soccer injuries: National Collegiate Athletic Association Injury Surveillance System, 1988-1989 through 2002-2003. J Athl Train 2007;42:278-285.

Ekstrand J, Hägglund M, Waldén M. Epidemiology of muscle injuries in professional football (soccer). Am J Sports Med 2011;39:1226-1232.

Hägglund M, Waldén M, Ekstrand J. Injury incidence and distribution in elite football-a prospective study of the Danish and the Swedish top divisions. Scand J Med Sci Sports 2005;15:21-28.

Hägglund M, Waldén M, Ekstrand J. Previous injury as a risk factor for injury in elite football: a prospective study over two consecutive sea- 
sons. Br J Sports Med 2006;40:767-772.

Hwang-Bo K, Joo CH. Analysis of injury incidences in the Korea national men's soccer teams. J Exerc Rehabil 2019;15:861-866.

Junge A, Dvorak J. Soccer injuries. Sports Med 2004;34:929-938.

Le Gall F, Carling C, Reilly T. Injuries in young elite female soccer players: an 8-season prospective study. Am J Sports Med 2008;36:276-284.

Pfirrmann D, Herbst M, Ingelfinger P, Simon P, Tug S. Analysis of injury incidences in male professional adult and elite youth soccer players: a systematic review. J Athl Train 2016;51:410-424.

Rampinini E, Coutts AJ, Castagna C, Sassi R, Impellizzeri FM. Variation in top level soccer match performance. Int J Sports Med 2007;28:10181024.

Roos KG, Wasserman EB, Dalton SL, Gray A, Djoko A, Dompier TP, Kerr ZY. Epidemiology of 3825 injuries sustained in six seasons of National
Collegiate Athletic Association men's and women's soccer (2009/20102014/2015). Br J Sports Med 2017;51:1029-1034.

Stevenson MR, Hamer P, Finch CF, Elliot B, Kresnow MJ. Sport, age, and sex specific incidence of sports injuries in Western Australia. Br J Sports Med 2000;34:188-194.

Stubbe JH, van Beijsterveldt AMM, van der Knaap S, Stege J, Verhagen EA, Van Mechelen W, Backx FJ. Injuries in professional male soccer players in the Netherlands: a prospective cohort study. J Athl Train 2015;50:211-216.

Waldén M, Hägglund M, Ekstrand J. The epidemiology of groin injury in senior football: a systematic review of prospective studies. Br J Sports Med 2015;49:792-797.

Wong P, Hong Y. Soccer injury in the lower extremities. Br J Sports Med 2005;39:473-482. 